\title{
Combinatorial Search for Green and Blue Phosphors of High Thermal Stabilities under UV Excitation Based on the $\mathrm{K}\left(\mathrm{Sr}_{1-x-y}\right) \mathrm{PO}_{4}: \mathrm{Tb}^{3+}{ }_{x} \mathrm{Eu}^{2+}{ }_{y}$ System
}

\author{
Ting-Shan Chan, ${ }^{\dagger, *}$ Yao-Min Liu ${ }^{\dagger}$ and Ru-Shi Liu*, ${ }^{\dagger}$ \\ Department of Chemistry, National Taiwan University, Taipei 106, Taiwan, and National Synchrotron \\ Radiation Research Center, Hsinchu 300, Taiwan
}

Received April 16, 2008

\begin{abstract}
The present investigation aims at the synthesis of $\mathrm{KSr}_{1-x-y} \mathrm{PO}_{4}: \mathrm{Tb}^{3+}{ }_{x} \mathrm{Eu}^{2+}{ }_{y}$ phosphors using the combinatorial chemistry method. We have developed square-type arrays consisting of 121 compositions to investigate the optimum composition and luminescence properties of $\mathrm{KSrPO}_{4}$ host matrix under $365 \mathrm{~nm}$ ultraviolet (UV) light. The optimized compositions of phosphors were found to be $\mathrm{KSr}_{0.93} \mathrm{PO}_{4}: \mathrm{Tb}^{3+}{ }_{0.07}$ (green) and $\mathrm{KSr}_{0.995} \mathrm{PO}_{4}$ : $\mathrm{Eu}^{2+}{ }_{0.005}$ (blue). These phosphors showed good thermal luminescence stability better than commercially available YAG:Ce at temperature above $200{ }^{\circ} \mathrm{C}$. The result indicates that the $\mathrm{KSr}_{1-x-y} \mathrm{PO}_{4}: \mathrm{Tb}^{3+}{ }_{x} \mathrm{Eu}^{2+}{ }_{y}$ can be potentially useful as a UV radiation-converting phosphor for light-emitting diodes.
\end{abstract}

\section{Introduction}

Solid-state lighting, which uses light-emitting diodes (LEDs) for illumination, has attracted significant attention in recent years. Compared to conventional incandescent and fluorescent lamps, LED-based white light sources are superior in longer lifetime, higher energy efficiency, reliability, and environmentally friendly characteristics. ${ }^{1-3}$ The present strategy to produce white light uses combination of blue LED with yellow luminescence from YAG: $\mathrm{Ce}^{3+}$ phosphor materials. ${ }^{4}$ However, this strategy faces serious problems of poor color rendition, narrow visible range, and thermal quenching. As an alternative, a novel approach has been suggested that uses UV excitation to generate white LED. Therefore, it is necessary to develop novel red, green, or blue (RGB) phosphors, exhibiting high color purity and thermal stability in the UV-LEDs. ${ }^{5}$

On the other hand, the combinatorial chemistry was used to rapidly survey a wide range of compositions of phosphors under a variety of processing conditions. ${ }^{6-14}$ Moreover, some reviews on combinatorial methods materials science can be found in the previous reports. ${ }^{15-17}$ In this regard, our present combinatorial approach investigates the optimization of $\mathrm{Y}_{2} \mathrm{O}_{3}: \mathrm{Bi}$, Eu red phosphors, which are excitable by $350-400$ nm UV light, and study their energy-transfer effect. ${ }^{18}$ In this paper, we focus on the combinatorial search for green and blue phosphors excitable by UV radiation based on the $\mathrm{K}\left(\mathrm{Sr}_{1-x-y}\right) \mathrm{PO}_{4}: \mathrm{Tb}^{3+}{ }_{x} \mathrm{Eu}^{2+}{ }_{y}$ system. The optimum concentration was evaluated by screening of 121 compositions. The optimum concentration was reproduced by conventional bulk solid-state synthesis, and powder samples were analyzed in detail to obtain structure, photoluminescence and thermal

* To whom correspondence should be addressed. E-mail: rsliu@ ntu.edu.tw.

Department of Chemistry.

$\doteqdot$ National Synchrotron Radiation Research Center. information. To the best of our knowledge, this is the first report to use combinatorial chemistry method assisted with solid state reaction to study $\mathrm{Tb}^{3+}$ and $\mathrm{Eu}^{2+}$ ions doped efficiently in a $\mathrm{KSrPO}_{4}$ host.

\section{Experimental Section}

The detailed schematic diagram of the drop-on-demand inkjet delivery system can be found in a previous report. ${ }^{18}$ The eight independent piezoelectric inkjet heads and $X-Y$ stage are controlled by the computer via the driving circuit and motor controller. Each inkjet head is connected to a suspension reservoir through a tube, and the substrate with a microreactor array is fixed on the stage. With the aid of a homemade inkjet delivery system, precursors $(>99.99 \%$ purity) such as $\mathrm{KH}_{2} \mathrm{PO}_{4}, \mathrm{Sr}\left(\mathrm{NO}_{3}\right)_{2}, \mathrm{Eu}\left(\mathrm{NO}_{3}\right)_{3} \cdot 5 \mathrm{H}_{2} \mathrm{O}$, and $\mathrm{Tb}\left(\mathrm{NO}_{3}\right)_{3} \cdot 5 \mathrm{H}_{2} \mathrm{O}$ were dissolved in deionizer water. Then the correct amount of each solution was collected in an $\mathrm{Al}_{2} \mathrm{O}_{3}$ ceramic substrate according to the composition map with the assistance of a computer-programmed inject system. The substrates containing the solutions were first dried at 100 ${ }^{\circ} \mathrm{C}$ for $1 \mathrm{~h}$ in an oven and then placed in a furnace where the temperature was slowly increased to $600{ }^{\circ} \mathrm{C}$ at the rate of $1{ }^{\circ} \mathrm{C} \mathrm{min}^{-1}$. Finally, the dried samples were pulverized and successively sintered at $1300{ }^{\circ} \mathrm{C}$ for $3 \mathrm{~h}$ under $5 \% \mathrm{H}_{2}$ $195 \% \mathrm{~N}_{2}$ atmosphere. The emission spectra of the samples in the library were measured using an automatic system. ${ }^{19}$ The main parts of the system consist of an Hg Lamp, a portable optical fiber spectrometer (Ocean Optics, Inc., model SD2000), and an $X-Y$ stage.

Two optimized compositions of $\mathrm{KSr}_{0.93} \mathrm{PO}_{4}: \mathrm{Tb}^{3+}{ }_{0.07}$ (green) and $\mathrm{KSr}_{0.995} \mathrm{PO}_{4}: \mathrm{Eu}^{2+}{ }_{0.005}$ (blue) phosphors were synthesized by conventional solid-state reaction using $\mathrm{KH}_{2} \mathrm{PO}_{4}, \mathrm{SrCO}_{3}$, and $\mathrm{Eu}_{2} \mathrm{O}_{3}$ as raw materials. Stoichiometric homogeneous mixtures of highly pure raw materials were obtained by thorough grinding. The mixture was first calcined in air at 


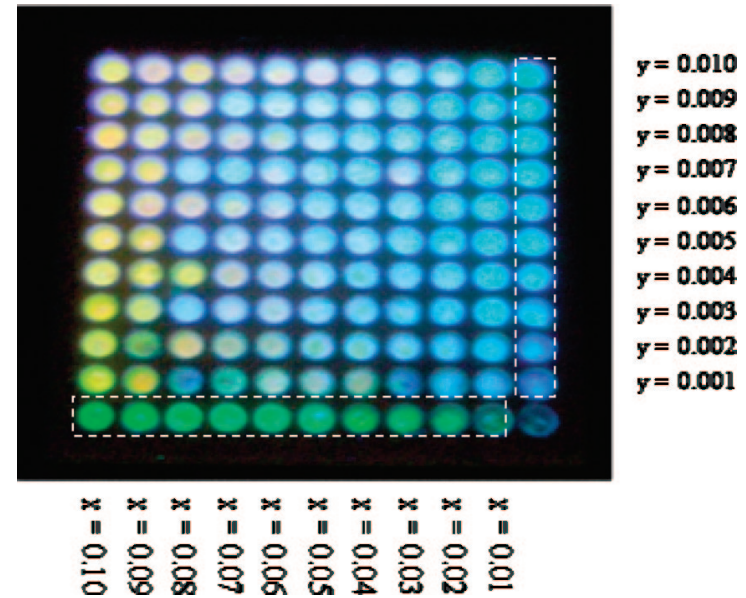

Figure 1. Composition map and photoluminescence photography of the library excited under $365 \mathrm{~nm}$ UV light for $\mathrm{KSr}_{1-x-y} \mathrm{PO}_{4}$ : $\mathrm{Tb}^{3+}{ }_{x} \mathrm{Eu}^{2+}{ }_{y}$.

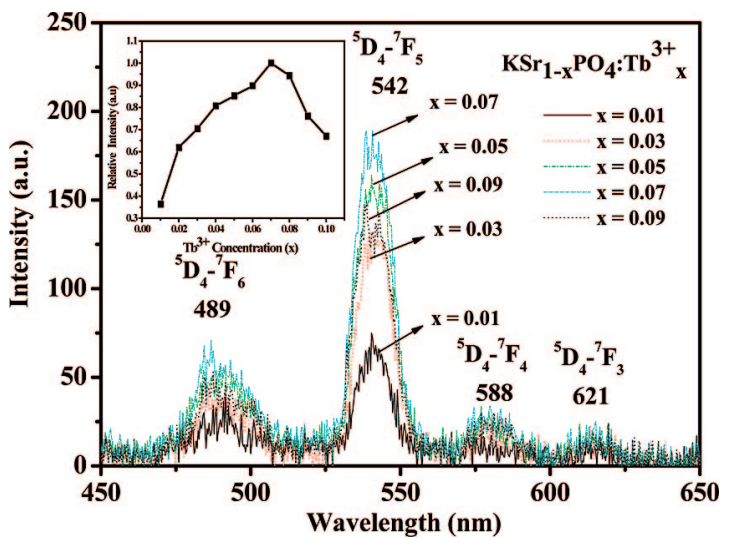

Figure 2. Emission spectra of $\mathrm{KSr}_{1-x} \mathrm{PO}_{4}: \mathrm{Tb}^{3+}{ }_{x}$ with different $\mathrm{Tb}^{3+}$ contents measured under $365 \mathrm{~nm}$ UV excitation. The normalized intensity as a function of $\mathrm{Tb}^{3+}$ concentration $(x)$ is shown in the inset.

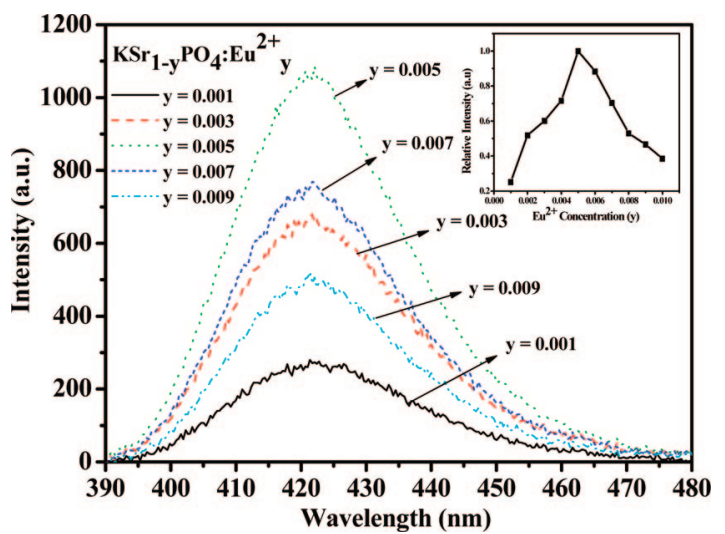

Figure 3. Emission spectrum of $\mathrm{KSr}_{1-y} \mathrm{PO}_{4}: \mathrm{Eu}_{y}{ }^{2+}$ with different $\mathrm{Eu}^{2+}$ contents measured under $365 \mathrm{~nm}$ UV excitation. The normalized intensity as a function of $\mathrm{Eu}^{2+}$ concentration (y) is shown in the inset.

$600{ }^{\circ} \mathrm{C}$ for $3 \mathrm{~h}$, followed by sintering in reductive atmosphere at $1300{ }^{\circ} \mathrm{C}$ for $3 \mathrm{~h}$ under $5 \% \mathrm{H}_{2} / 95 \% \mathrm{~N}_{2}$ atmosphere. The crystal structure and phase purity of the synthesized samples were identified by X-ray diffraction (XRD) analysis using X'Pert PRO advanced automatic diffractometer with $\mathrm{Cu} K \alpha$ radiation operated at $45 \mathrm{kV}$ and $40 \mathrm{~mA}$. The GSAS program $^{20}$ was used for the Rietveld refinements to obtain the information on the crystal structures. The photolumines-
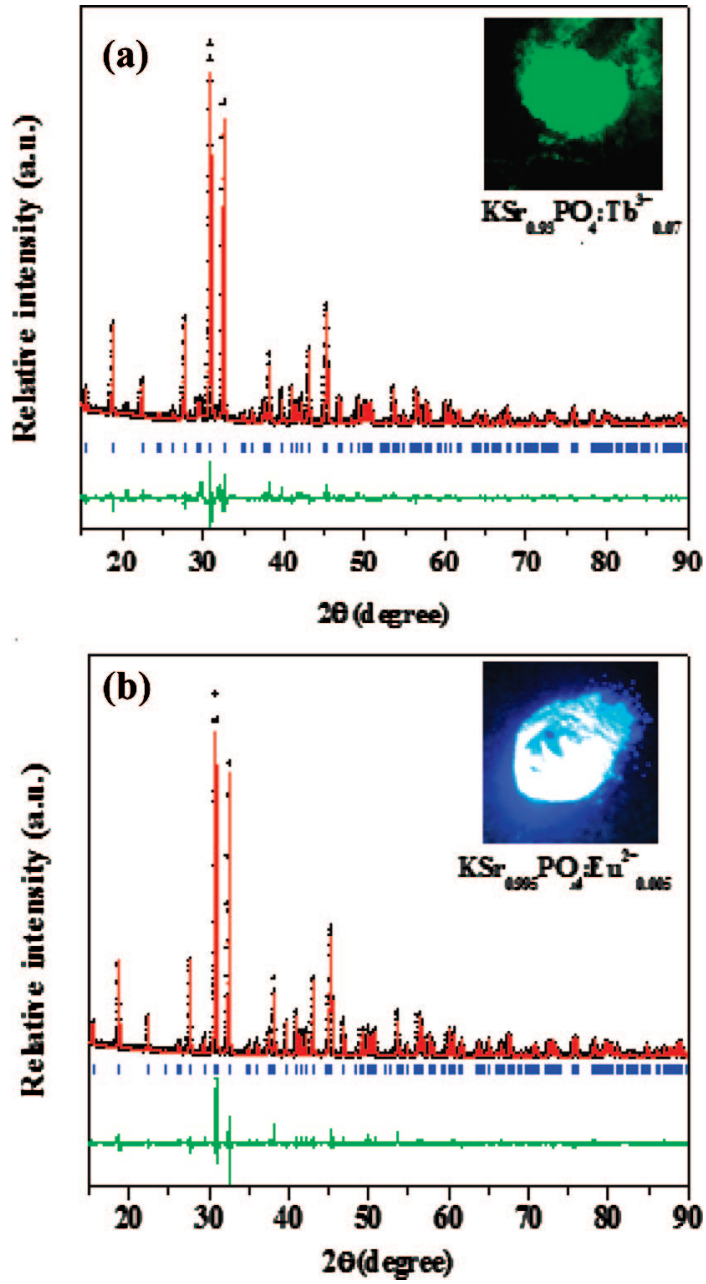

Figure 4. Observed (crosses), calculated (solid line), and differences (bottom) XRD Rietveld profiles of (a) $\mathrm{KSr}_{0.93} \mathrm{PO}_{4}: \mathrm{Tb}^{3+}{ }_{0.07}$ and (b) $\mathrm{KSr}_{0.995} \mathrm{PO}_{4}: \mathrm{Eu}^{2+}{ }_{0.005}$ at $300 \mathrm{~K}$ with $\lambda=1.5406 \AA$, respectively. Bragg reflections are indicated by tick marks.

cence (PL) of the samples were measured by using a FluoroMax-3 and FluoroMax-P. Thermal quenching measurements were investigated using a heating apparatus (THMS-600) in combination with the PL equipment.

\section{Results and Discussion}

The composition map and luminescent photograph of $\mathrm{K}\left(\mathrm{Sr}_{1-x-y}\right) \mathrm{PO}_{4}: \mathrm{Tb}^{3+}{ }_{x} \mathrm{Eu}^{2+}{ }_{y}$ library under 365 nm UV excitation are shown in Figure 1. The square-type arrays consist of 121 compositions with co-doped different $\mathrm{Tb}^{3+}$ contents from $x=0.01$ to 0.1 and $\mathrm{Eu}^{2+}$ contents from $y=0.001$ to 0.01 . It is well-known that energy transfer is not possible between $\mathrm{Tb}^{3+}\left(4 \mathrm{f}-4 \mathrm{f}\right.$ forbidden transition) and $\mathrm{Eu}^{2+}(5 \mathrm{~d}-4 \mathrm{f}$ allowed transitions) because of the energy level. Hence, to clearly display the variation, in this paper we only focus on the high color purity green and blue phosphors (white area) by $\mathrm{Tb}^{3+}$ and $\mathrm{Eu}^{2+}$ doping, respectively, and ignore the effect of codoping.

Figure 2 presents the emission spectra of $\mathrm{KSr}_{1-\mathrm{x}} \mathrm{PO}_{4}: \mathrm{Tb}_{\mathrm{x}}{ }^{3+}$ $(x=0.01,0.03,0.05,0.07$ and 0.09$)$, which varies with the $\mathrm{Tb}^{3+}$ contents in the library. The overall normalized intensity from $\lambda=542 \mathrm{~nm}$ according to Figure 2 is shown in the inset. The optimized composition of green phosphor was found to be $\mathrm{KSr}_{0.93} \mathrm{PO}_{4}: \mathrm{Tb}^{3+}{ }_{0.07}$. Under $365 \mathrm{~nm} \mathrm{UV} \mathrm{light}$ 
Table 1. Crystallographic Data for $\mathrm{KSr}_{0.93} \mathrm{PO}_{4}: \mathrm{Tb}^{3+}{ }_{0.07}$ and $\mathrm{KSr}_{0.995} \mathrm{PO}_{4}: \mathrm{Eu}^{2+}{ }_{0.005}$ Phosphors

\begin{tabular}{|c|c|c|c|}
\hline \multicolumn{2}{|c|}{$\mathrm{KSr}_{0.93} \mathrm{PO}_{4}: \mathrm{Tb}^{3+}{ }_{0.07}$} & \multicolumn{2}{|c|}{$\mathrm{KSr}_{0.995} \mathrm{PO}_{4}: \mathrm{Eu}^{2+}{ }_{0.005}$} \\
\hline space group & $\begin{array}{c}\text { Pnma } \\
\text { (orthorhombic) }\end{array}$ & $\begin{array}{l}\text { Space grou } \\
\text { (orthorh }\end{array}$ & $\begin{array}{l}\text { Pnma } \\
\text { nbic) }\end{array}$ \\
\hline cell parameter & & Cell par & neter \\
\hline$a$ & 7.3665 (1) A & $a$ & 7.3679 (3) A \\
\hline$b$ & $5.5683(1) \AA$ & $b$ & $5.5661(2) \AA$ \\
\hline$c$ & 9.6354 (2) $\AA$ & $c$ & 9.6431 (4) $\AA$ \\
\hline$\alpha=\beta=\gamma$ & $90^{\circ}$ & $\alpha=\beta=\gamma$ & $90^{\circ}$ \\
\hline $\begin{array}{l}\text { cell volume } \\
\text { reliability factors }\end{array}$ & $395.23(1) \AA^{3}$ & $\begin{array}{l}\text { cell volume } \\
\text { reliability factors }\end{array}$ & $395.47(3) \AA^{3}$ \\
\hline$\chi^{2}$ & 1.5 & $\chi^{2}$ & 1.6 \\
\hline$\stackrel{R}{\mathrm{p}}_{R}$ & $3.1 \%$ & $R_{\mathrm{p}}$ & $3.1 \%$ \\
\hline$R_{\mathrm{wp}}$ & $4.8 \%$ & $R_{\mathrm{wp}}$ & $4.9 \%$ \\
\hline
\end{tabular}

\begin{tabular}{lrcrc}
\hline \multicolumn{5}{c}{$\mathrm{KSr}_{0.93} \mathrm{PO}_{4}: \mathrm{Tb}^{3+}{ }_{0.07}$} \\
\hline atoms & \multicolumn{1}{c}{$x$} & \multicolumn{1}{c}{$y$} & \multicolumn{1}{c}{$z$} & $U_{\text {iso }}\left(\AA^{2}\right)$ \\
\hline $\mathrm{K}$ & 0.15870 & 0.25000 & 0.58407 & 0.30 \\
$\mathrm{Sr}$ & -0.00400 & 0.25000 & 0.19735 & 1.62 \\
$\mathrm{P}$ & 0.22613 & 0.25000 & -0.08995 & 0.73 \\
$\mathrm{O}(1)$ & 0.30961 & 0.25000 & 0.05847 & 1.31 \\
$\mathrm{O}(2)$ & 0.29726 & 0.03013 & 0.84571 & 0.92 \\
$\mathrm{O}(3)$ & 0.52338 & 0.25000 & 0.58475 & 0.66 \\
$\mathrm{~Tb}$ & -0.00400 & 0.25000 & 0.19735 & 1.62 \\
& \multicolumn{5}{c}{} \\
\hline \multicolumn{5}{c}{$\mathrm{KSr}_{0.995} \mathrm{PO}_{4}: \mathrm{Eu}^{2+} 0.005$} \\
atoms & $x$ & & \\
\hline $\mathrm{K}$ & 0.16120 & 0.25000 & 0.58502 & 1.90 \\
$\mathrm{Sr}$ & -0.00299 & 0.25000 & 0.19655 & 1.01 \\
$\mathrm{P}$ & 0.23382 & 0.25000 & -0.07686 & 2.02 \\
$\mathrm{O}(1)$ & 0.31376 & 0.25000 & 0.06391 & 0.46 \\
$\mathrm{O}(2)$ & 0.28799 & 0.01393 & 0.85075 & 1.55 \\
$\mathrm{O}(3)$ & 0.52190 & 0.25000 & 0.59014 & 2.13 \\
$\mathrm{Eu}$ & -0.00299 & 0.25000 & 0.19655 & 1.01 \\
\hline
\end{tabular}

excitation, the major emission peak centering at $542 \mathrm{~nm}$ corresponds to ${ }^{5} \mathrm{D}_{4}-{ }^{7} \mathrm{~F}_{5}$ transition, while ${ }^{5} \mathrm{D}_{4}-{ }^{7} \mathrm{~F}_{6},{ }^{5} \mathrm{D}_{4}-{ }^{7} \mathrm{~F}_{4}$, and ${ }^{5} \mathrm{D}_{4}-{ }^{7} \mathrm{~F}_{3}$ transition can be assigned to the emission peaks at $489,588,621 \mathrm{~nm}$, respectively.

The emission spectra of $\mathrm{KSr}_{1-y} \mathrm{PO}_{4}: \mathrm{Eu}_{y}{ }^{2+}(y=0.001$, $0.003,0.005,0.007$, and 0.009) under $365 \mathrm{~nm}$ UV light excitation with different $\mathrm{Eu}^{2+}$ contents are shown in Figure 3. The overall normalized intensity from $\lambda=424 \mathrm{~nm}$ according to Figure 3 is also shown in the inset. The optimized composition of blue phosphor was found to be $\mathrm{KSr}_{0.995} \mathrm{PO}_{4}: \mathrm{Eu}^{2+}{ }_{0.005}$. The broad emission spectra with full

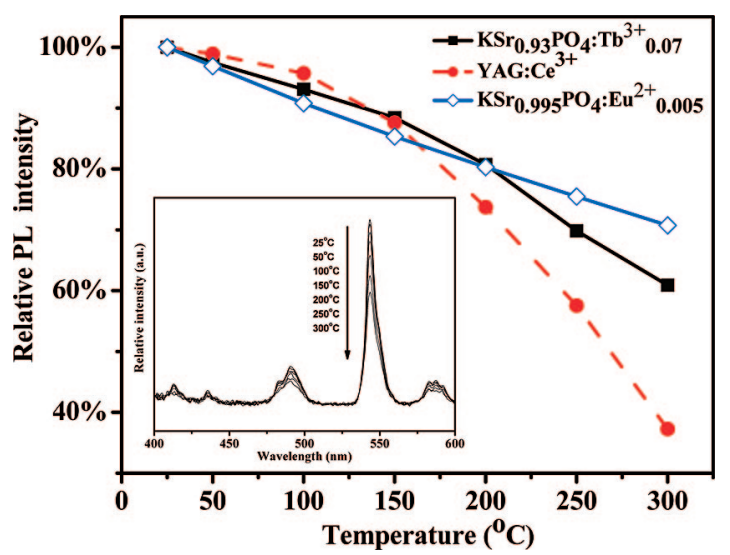

Figure 5. Temperature-dependent relative intensity of $\mathrm{KSr}_{0.93} \mathrm{PO}_{4}$ : $\mathrm{Tb}^{3+}{ }_{0.07}, \mathrm{KSr}_{0.995} \mathrm{PO}_{4}: \mathrm{Eu}^{2+}{ }_{0.005}$, and commercially available YAG: $\mathrm{Ce}^{3+}$ phosphors. The select emission spectra as a function of temperature of $\mathrm{KSr}_{0.93} \mathrm{PO}_{4}: \mathrm{Tb}^{3+}{ }_{0.07}$ are show in the inset. width at half-maximum about $32 \mathrm{~nm}$ can be attributed to $5 \mathrm{~d}-4 \mathrm{f}$ allowed transitions of $\mathrm{Eu}^{2+}$ ions.

Figure $4 \mathrm{a}$ and $\mathrm{b}$ shows observed (crossed), calculated (solid line), and difference (bottom) in XRD patterns of $\mathrm{KSr}_{0.93} \mathrm{PO}_{4}$ : $\mathrm{Tb}^{3+}{ }_{0.07}$ and $\mathrm{KSr}_{0.995} \mathrm{PO}_{4}: \mathrm{Eu}^{2+}{ }_{0.005}$ phosphors at $300 \mathrm{~K}$ with $\lambda=1.5406 \AA$, respectively. Photographs for the $\mathrm{KSr}_{0.93} \mathrm{PO}_{4}$ : $\mathrm{Tb}^{3+}{ }_{0.07}$ (green) and $\mathrm{KSr}_{0.995} \mathrm{PO}_{4}: \mathrm{Eu}^{2+}{ }_{0.005}$ (blue) phosphors under $365 \mathrm{~nm}$ UV light excitation are also shown in the inset. The observed peaks can be indexed on the basis of orthorhombic unit cell (space group Pnma), which is consistent with the JCPDS number-331045. The final structural parameters are given in Table 1. As noted from Table 1, Rietveld analysis afforded sufficiently low $R$ factors for these two samples. Therefore, the optimization process by combinatorial chemistry method assisted with solid state reaction has been finely applied to novel phosphors development.

Figure 5 shows the temperature-dependent relative intensity of $\mathrm{KSr}_{0.93} \mathrm{PO}_{4}: \mathrm{Tb}^{3+}{ }_{0.07}$ (excitation at $365 \mathrm{~nm}$ and monitored at $542 \mathrm{~nm}$ ), $\mathrm{KSr}_{0.995} \mathrm{PO}_{4}: \mathrm{Eu}^{2+}{ }_{0.005}$ (excitation at $365 \mathrm{~nm}$ and monitored at $424 \mathrm{~nm}$ ), and commercially YAG: $\mathrm{Ce}^{3+}$ (excitation at $460 \mathrm{~nm}$ and monitored at $550 \mathrm{~nm}$ ) phosphors. The selected emission spectra as a function of temperature of $\mathrm{KSr}_{0.93} \mathrm{PO}_{4}: \mathrm{Tb}^{3+}{ }_{0.07}$ are also shown in the inset. As seen from Figure 5, the relative peak intensity decreases from initial $100 \%$ at $30{ }^{\circ} \mathrm{C}$ to $\sim 62 \%\left(\mathrm{KSr}_{0.93} \mathrm{PO}_{4}\right.$ : $\left.\mathrm{Tb}^{3+}{ }_{0.07}\right), \sim 72 \%\left(\mathrm{KSr}_{0.995} \mathrm{PO}_{4}: \mathrm{Eu}^{2+}{ }_{0.005}\right.$ ), and $\sim 38 \%$ (YAG: $\mathrm{Ce}^{3+}$ ) at $300{ }^{\circ} \mathrm{C}$, respectively. The result indicated that the thermal luminescence stability of $\mathrm{KSr}_{0.93} \mathrm{PO}_{4}: \mathrm{Tb}^{3+}{ }_{0.07}$ (green) and $\mathrm{KSr}_{0.995} \mathrm{PO}_{4}: \mathrm{Eu}^{2+}{ }_{0.005}$ (blue) phosphors above $200{ }^{\circ} \mathrm{C}$ was higher than the commercially available YAG: $\mathrm{Ce}^{3+}$.

\section{Conclusion}

We have synthesized green and blue phosphate phosphors for $\mathrm{K}\left(\mathrm{Sr}_{1-x-y}\right) \mathrm{PO}_{4}: \mathrm{Tb}^{3+}{ }_{x} \mathrm{Eu}^{2+}{ }_{y}$ by using the combinatorial chemistry method. The two optimum compositions were found to be $\mathrm{KSr}_{0.93} \mathrm{PO}_{4}: \mathrm{Tb}^{3+}{ }_{0.07}$ (green) and $\mathrm{KSr}_{0.995} \mathrm{PO}_{4}$ : $\mathrm{Eu}^{2+}{ }_{0.005}$ (blue). To confirm the composition and characterization of the structure and thermal luminescence properties in detail, the samples were synthesized through solid-sate reaction under the same condition. We demonstrate that the thermal stabilities of $\mathrm{K}\left(\mathrm{Sr}_{1-x-y}\right) \mathrm{PO}_{4}: \mathrm{Tb}^{3+}{ }_{x} \mathrm{Eu}^{2+}{ }_{y}$ are higher than the commercially YAG:Ce ${ }^{3+}$. On the basis of the above results, it is reasonable to believe that the developed combinatorial chemistry method makes the search for high efficiency phosphors for use in UV-LEDs possible.

Acknowledgment. We thank the National Science Council of Taiwan (Grant NSC 96-2120-M-002-019) and the Ministry of Economic Affair of Taiwan. (Grant 96-EC-17-A-07-S1043) for financial supports.

\section{References and Notes}

(1) Neeraj, S.; Kijima, N.; Cheetham, A. K. Chem. Phys. Lett. 2004, 387, 2.

(2) Nishida, T.; Ban, T.; Kobayashi, N. Appl. Phys. Lett. 2003, 82, 3817.

(3) Kim, J. S.; Jeon, P. E.; Choi, J. C.; Park, H. L.; Mho, S. I.; Kim, G. C. Appl. Phys. Lett. 2004, 84, 2931.

(4) Nakamura, S.; Fasol, G. The Blue Laser Diode: GaN Based Light Emitters Lasers; Springer: Berlin, 1997. 
(5) Shimizu, Y.; Sakano, K.; Noguchi, Y.; Moriguchi, T. U.S. Patent 5,998,925, 1999.

(6) Sun, X. D.; Gao, C.; Wang, J.; Xiang, X.-D. Appl. Phys. Lett. 2007, 70, 3353.

(7) Wang, J.; Yoo, Y.; Gao, C.; Takeuchi, I.; Sun, X.; Chang, H.; Xinag, X.-D.; Schultz, P. G. Science 1998, 279, 1712.

(8) Sohn, K. S; Park, E. S.; Kim, C. H.; Park, H. D. J. Electrochem. Soc. 2000, 147, 4368.

(9) Sohn, K. S.; Seo, S. Y.; Park, H. D. Electrochem. Solid-State Lett. 2001, 4, H26.

(10) Sohn, K. S.; Kim, C. H.; Park, J. T.; Park, H. D. J. Mater. Res. 2002, 17, 3201.

(11) Seo, S. Y.; Sohn, K. S.; Park, H. D.; Lee, S. J. Electrochem. Soc. 2002, 149, H12.

(12) Chen, L.; Bao, J.; Gao, C. J. Comb. Chem. 2004, 6, 699.

(13) Luo, Z. L.; Geng, B.; Bao, J.; Gao, C. J. Comb. Chem. 2005, 7, 942 .
(14) Sohn, K. S.; Park, D. H.; Cho, S. H.; Kim, B. I.; Woo, S. I. J. Comb. Chem. 2006, 8, 44.

(15) Jandeleit, B.; Schaefer, D. J.; Powers, T. S.; Turner, H. W.; Weinberg, W. H. Angew. Chem., Int. Ed. 1999, 38, 2494.

(16) Michael, A. R. M. R. H.; Ulrich, S. S. Macromol. Rapid Commun. 2003, 24, 16.

(17) Stefan, S.; Michael, A. R. M.; Ulrich, S. S. Macromol. Rapid Commun. 2004, 25, 21.

(18) Chan, T. S.; Kang, C. C.; Liu, R. S.; Chen, L.; Liu, X. N.; Ding, J. J.; Bao, J.; Gao, C. J. Comb. Chem. 2007, 9, 343.

(19) Chen, L.; Bao, J.; Gao, C. J. Comb. Chem 2004, 6, 699.

(20) Larson, A. C.; Von Dreele, R. B. Generalized Structure Analysis System (GSAS); Report LAUR 86-748; Los Alamos National Laboratory: Los Alamos, NM, 1994.

CC800060X 